\title{
Direct analysis of eight chlorophenols in urine by large volume injection online turbulent flow solid-phase extraction liquid chromatography with multiple wavelength ultraviolet detection
}

\author{
Feng Guo ${ }^{\mathrm{a}}$, Qian Liu ${ }^{\mathrm{a}}$, Jian-bo Shi ${ }^{\mathrm{a}, *}$, Fu-sheng Wei ${ }^{\mathrm{a}, \mathrm{b}}$, Gui-bin Jiang ${ }^{\mathrm{a}}$ \\ a State Key Laboratory of Environmental Chemistry and Ecotoxicology, Research Center for Eco-Environmental Sciences, Chinese Academy of Sciences, \\ Beijing 100085, China \\ b China National Evironmental Monitoring Center, Beijing, 100012, China
}

\section{A R T I C L E I N F O}

\section{Article history:}

Received 29 August 2013

Received in revised form

23 October 2013

Accepted 1 November 2013

Available online 19 November 2013

\section{Keywords}

Turbulent flow chromatography

Online solid-phase extraction

Chlorophenols

Urine

\begin{abstract}
A B S T R A C T
A novel method for determining eight chlorophenols (CPs) by large volume injection online turbulent flow solid-phase extraction high performance liquid chromatography in urine samples was developed. An aliquot of $1.0 \mathrm{~mL}$ urine sample could be analyzed directly after centrifugation. The analytes were preconcentrated online on a Turboflow C18-P SPE column, eluted in back-flush mode, and then separated on an Acclaim PA2 analytical column. Major parameters such as SPE column type, sample loading flow rate and elution time were optimized in detail. Eight CPs from monochlorophenol to pentacholophenol were measured by multiple-wavelength UV detection at four different wavelengths. The limits of detection (LODs) were between 0.5 and $2 \mathrm{ng} / \mathrm{mL}$. The linearity range was from the limit of quantification to $1000 \mathrm{ng} / \mathrm{mL}$ for each compound, with the coefficients of determination $\left(r^{2}\right)$ ranging from 0.9990 to 0.9996 . The reproducibility of intraday and interday relative standard deviations (RSDs) ranged from $0.6 \%$ to $4.5 \%(n=5)$. The method was successfully applied to analyze eight CPs in urine samples. Good recoveries, ranging from $76.3 \%$ to $122.9 \%$, were obtained. This simple, sensitive and accurate method provides an alternative way to rapidly analyze and monitor CPs in urine samples, especially for matters of occupational exposure.
\end{abstract}

(c) 2013 Elsevier B.V. All rights reserved.

\section{Introduction}

Chlorophenols (CPs) have been widely used as raw materials or intermediates for dyes, fungicides, pesticides, insecticides, and herbicides [1-3]. They are also used in the leather- and woodpreservation industries [4]. In addition, tap water chlorination may produce CPs [5]. These compounds are potential estrogens or carcinogenic [6-8] to human health, and may interfere with oxidative phosphorylation and inhibit ATP synthesis [1]. Substances such as 2-chlorophenol, 2, 4-dichlorophenol, 2, 4, 6-trichlorophenol, and pentachlorophenol have been regulated as priority pollutants by the U.S. Environmental Protection Agency (EPA). Highly chlorinated phenols are persistent $[9,10]$. Many countries and international organizations $[11,12]$ have limited their maximum concentrations in drinking water. CPs can easily enter the human body via dermal, dietary, or aqueous absorption [13], and are partially excreted via urine. Studies on human or environmental exposures to these highly toxic compounds are ongoing [14-16]. Since human exposures to

\footnotetext{
* Corresponding author. Tel./fax: +86 1062849129.

E-mail address: jbshi@rcees.ac.cn (J.-b. Shi).
}

these compounds can be assessed by measuring them in urine, CPs in urine were frequently analyzed and monitored as xenobiotic indicators for metabolism studies or occupational exposures [17-19].

Gas chromatography (GC) and high performance liquid chromatography (HPLC) are commonly used methods to measure CPs in environmental [5,9,20-22] and biological samples [23-25]. HPLC is more convenient and more robust than GC [26,27] because it does not require complicated derivatization. Fully automated online solid-phase extraction (SPE) coupled liquid chromatography methods [28-30] with simple pretreatment can further simplify the operations and release the operators from tedious work, so they are useful for rapidly screening controlled pollutants in diverse fluid samples.

The online Turboflow column is a kind of novel columns for online preconcentration, which is very effective for direct and fast analyzing complicated biological fluids, such as urine, serum and saliva [31-33]. Currently, this technique is mainly used for analysis of drugs and biomarkers. By using turbulent flow liquid chromatography tandem mass spectrometry (LC-MS/MS), the terbinafine in plasma have been directly analyzed, and the throughput was significantly improved [34]. The turbulent flow LC-MS/MS method was also successfully applied for simultaneous analysis of a broad 
range of controlled drugs in urine in a short cycle time [35]. In addition, the applications of turbulent flow column in analyzing drugs and toxins in wine, milk, and meat production were also developed. However, only a few studies [36,37] refer to its application for environmental pollutants.

The aim of this work was to develop a fully automated method for directly measuring eight CPs in urine samples with large volume injection online turbulent flow solid-phase extraction high performance liquid chromatography (SPE-LVI-HPLC). A large volume $(1.0 \mathrm{~mL})$ urine sample could be injected directly after centrifugation. Eight CPs, including two monochlorophenol isomers, three dichlorophenol isomers, one trichlorophenol, one tetrachlorophenol, and one pentachlorophenol were trapped on the Turboflow C18-P column, eluted in back-flush mode, and further separated on an Acclaim PA2 analytical column. The proposed method has been successfully applied to analyze twenty urine samples of healthy adults.

\section{Experimental section}

\subsection{Chemicals and materials}

Standards for 3-chlorophenol (3-CP, 99\%), 2,4-dichlorophenol, (2,4-DCP, 99\%), 3,4-dichlorophenol (3,4-DCP, 99\%), and 2,4,6-trichlorophenol (2,4,6-TCP, 98\%) were purchased from Acros Organics (Geel, Belgium). 4-Chlorophenol (4-CP, 100\%) was purchased from AccuStandard (New Haven, CT). 2,3-Dichlorophenol (2,3-DCP, 98\%) was purchased from Alfa Aesar. 2,3,5,6-Tetrachlorophenol (2,3,5,6-TeCP, 98\%) was purchased from Sigma (St. Louis, MO). Pentachlorophenol (PCP) was purchased from Dr. Ehrenstorfer (Augsburg, Germany). Their molecular structures are shown in Fig. 1.

Stock solutions $(2000 \mathrm{mg} / \mathrm{mL})$ were prepared in methanol $(\mathrm{MeOH})$ and stored in the dark at $4{ }^{\circ} \mathrm{C}$. Working solutions were freshly prepared by diluting the stock solutions with water. HPLC grade Acetonitrile were all purchased from J.T. Baker (Phillipsburg, NJ). Ultrapure water produced from a Milli-Q system (Millipore, Billerica, MA) was used throughout. All reagents were of analytical grade unless otherwise noted.

\subsection{Online SPE procedure and HPLC analysis}

The UltiMate 3000 system (Thermo, USA) was controlled by Chromeleon $^{\circledR}$ Chromatography Management Software (v. 6.80, Dionex, USA). This system consisted of a WPS-3000TSL<smiles>Oc1ccc(Cl)cc1</smiles><smiles>Oc1ccc(Cl)cc1Cl</smiles><smiles>Oc1ccc(Cl)c(Cl)c1</smiles>

3,4-DCP<smiles>Oc1c(Cl)cc(Cl)cc1Cl</smiles><smiles>Oc1c(Cl)c(Cl)cc(Cl)c1Cl</smiles><smiles>Oc1c(Cl)c(Cl)c(Cl)c(Cl)c1Cl</smiles>

Fig. 1. Chemical structures of the eight CPs.

Table 1

Online SPE procedure, HPLC gradient elution and valve switching program.

\begin{tabular}{|c|c|c|c|c|c|c|c|}
\hline \multirow[t]{2}{*}{ Time $(\min )$} & \multicolumn{3}{|c|}{ Pump 1} & \multicolumn{3}{|c|}{ Pump 2} & \multirow{2}{*}{$\begin{array}{l}\text { Valve } \\
\text { position }\end{array}$} \\
\hline & $A(\%)$ & $B(\%)$ & $\begin{array}{l}\text { Flow rate } \\
(\mathrm{mL} / \mathrm{min})\end{array}$ & $A(\%)$ & $B(\%)$ & $\begin{array}{l}\text { Flow rate } \\
(\mathrm{mL} / \mathrm{min})\end{array}$ & \\
\hline-0.5 & 0 & 10 & 3.0 & 75 & 25 & 0.7 & 1 \\
\hline 0.0 & 90 & 10 & 3.0 & 75 & 25 & 0.7 & 1 \\
\hline 0.1 & 90 & 10 & 1.0 & 75 & 25 & 0.7 & 1 \\
\hline 1.1 & 90 & 10 & 1.0 & 74 & 26 & 0.7 & 2 \\
\hline 6.1 & 90 & 10 & 0.7 & 68 & 32 & 0.7 & 1 \\
\hline 17.0 & 90 & 10 & 0.7 & 55 & 45 & 0.7 & 1 \\
\hline 18.0 & 90 & 10 & 0.7 & 55 & 45 & 0.7 & 1 \\
\hline 28.0 & 90 & 10 & 0.7 & 10 & 90 & 0.7 & 1 \\
\hline 28.5 & 90 & 10 & 3.0 & 10 & 90 & 0.7 & 1 \\
\hline 29.0 & 90 & 10 & 3.0 & 10 & 90 & 0.7 & 1 \\
\hline 29.1 & 90 & 10 & 3.0 & 75 & 25 & 0.7 & 1 \\
\hline 31.0 & 90 & 10 & 3.0 & 75 & 25 & 0.7 & 1 \\
\hline
\end{tabular}

“ -0.5 ” stands for sample loading time before the start time of baseline acquisition (recorded as "0")

Mobile phase: A, $25 \mathrm{mM} \mathrm{HAc} / 25 \mathrm{mM} \mathrm{NH}_{4} \mathrm{Ac}(1.45: 1, \mathrm{v} / \mathrm{v})$; B, ACN.

autosampler with large-volume loop $(2.5 \mathrm{~mL})$ for injection, a TCC-3200 thermostated column compartment with a two-position, six-port (2P-6P) valve, a DGP 3600M dual-gradient pump, and a SRD 3600 solvent rack with integrated vacuum degasser.

The setup and method procedures are similar to our previous study [38]. Briefly, five major steps were used: sampling, cleanup, SPE column regeneration, elution and HPLC separation. Each $1.0 \mathrm{~mL}$ sample was drawn by syringe from a $1.5 \mathrm{~mL}$ vial and pumped into the large-volume loop, and then delivered to the online SPE column (Turboflow C18-P, $60 \mu \mathrm{m}, 1.0 \times 50 \mathrm{~mm}$, Thermo Scientific) with a high flow rate mobile phase $(3 \mathrm{~mL} / \mathrm{min}, 90 \% \mathrm{~A})$ for the pump 1 . After sampling, the flow rate was changed to $1 \mathrm{~mL} / \mathrm{min}$ and kept for $1 \mathrm{~min}$ to remove matrix components concentrated on the SPE column together with the analytes. After cleanup, the valve was switched to elute the analytes from the SPE column to the analytical column by the mobile phase (25\% B) for 5 min in back-flush mode. Then the valve was transferred back and the analytes were further separated on an analytical column (Acclaim ${ }^{\circledR}$ PA2, $3 \mu \mathrm{m}, 3.0 \times 150 \mathrm{~mm}$, Thermo Scientific). Meanwhile, the SPE column was regenerated for next analysis. The mobile phase consisted of (A) $25 \mathrm{mM} \mathrm{HAc} / 25 \mathrm{mM} \mathrm{NH}_{4} \mathrm{Ac}$ (1.45:1, $\mathrm{v} / \mathrm{v}$ ) and (B) acetonitrile (ACN) for both pumps. The analytical column temperature was set at $40{ }^{\circ} \mathrm{C}$. The online SPE procedure for the pump 1 , schedules of valve switching, gradient elution and separation condition for the pump 2 are listed in Table 1. The SPE column was regenerated after each elution step in order to remove any residual contamination so that the method will be reproducible. Flushing with 10\% B for 22 min was enough for this. Multiple wavelength UV detection (Dionex, USA) was used in quantifying CPs: $269 \mathrm{~nm}$ for 4-CP, $277 \mathrm{~nm}$ for 3-CP, $286 \mathrm{~nm}$ for 2,3-DCP, 2,4-DCP, 3,4-DCP and 2,4,6-TCP, and $303 \mathrm{~nm}$ for 2,3,5,6-QCP and PCP. At the same time, 3D scanning was used to obtain the spectrograms of the analytes and identify them.

\section{Results and discussion}

\subsection{HPLC analysis}

HPLC parameters were optimized to ensure proper resolution, symmetry, and adequate separation of the eight CPs. The analytical column was an Acclaim PA2 $(3 \mu \mathrm{m}, 3.0 \times 150 \mathrm{~mm}$, Thermo Scientific). With an acetonitrile/water mixture as the mobile phase, the Acclaim PA2 column resolved the analytes well. Slower elution from $25 \%(\mathrm{v} / \mathrm{v})$ ACN to $45 \%(\mathrm{v} / \mathrm{v}) \mathrm{ACN}$ in 17 minutes separated the eight CPs better, especially for the two groups of isomers. 
A gradient elution from $45 \%(\mathrm{v} / \mathrm{v}) \mathrm{ACN}$ to $90 \%(\mathrm{v} / \mathrm{v}) \mathrm{ACN}$ in $10 \mathrm{~min}$ was needed for fast elution of the strongly retained analytes. Good peak shape and baseline separation of all analytes were obtained without a buffer for the standard solutions, but poor recoveries were obtained for real urine samples. Since an acidic $\mathrm{pH}$ was suitable for CPs, a $25 \mathrm{mM} \mathrm{HAc} / 25 \mathrm{mM} \mathrm{NH}_{4} \mathrm{Ac}(1.45: 1$, v/v) buffer was added to the mobile phase, as suggested in the literature [39]. The final gradient elution and its related parameters are listed in Table 1.

\subsection{Selection of Turboflow SPE column and sample volume}

Turboflow columns packed with big particles $(60 \mu \mathrm{m})$ provide an efficient separation of large matrix components from smaller molecules when the fluid in the column is turbulent. Macromolecules such as proteins may be excluded from the Turboflow column, and have no time to diffuse into the pores of particles and interact with stationary phase chemistry at a relatively high flow rate [31,37], which was optimized (Section 3.3).

Two types of commercial columns were compared, including silica-based Turboflow C18-P $(60 \mu \mathrm{m}, 1.0 \times 50 \mathrm{~mm}$, Thermo Scientific) and polymeric Turboflow Cyclone-P $(60 \mu \mathrm{m}, 1.0 \times 50 \mathrm{~mm}$, Thermo Scientific). Each of them retains polar and nonpolar compounds. The extraction efficiencies of the two SPE columns were evaluated by comparing the peak areas obtained from online analysis of standard solutions. The online analysis of $1 \mu \mathrm{g} / \mathrm{mL}$ standard solutions was run in replicate batches $(n=5)$. Other parameters in this step were: $100 \mu \mathrm{L}$ of sample volume, samples cleaned up with $10 \% \mathrm{ACN}(\mathrm{v} / \mathrm{v})$ for $1 \mathrm{~min}$, and sample loading flow rates of $2 \mathrm{ml} / \mathrm{min}$. The extraction efficiencies for the eight CPs with the two different SPE columns are shown in Fig. 2. The Turboflow C18-P column was eventually selected because it gave better extraction efficiencies for 2,3-DCP, 2,4-DCP, 2,4,6-TCP, 2,3,5,6-TeCP, and PCP, as well as comparable results for 3-CP, 4-CP, and 3,4-BCP.

A small volume injection (from $20 \mu \mathrm{L}$ to $200 \mu \mathrm{L}$ ) was normally used in HPLC analysis [35,40]. In this work, the sample volume was increased from $100 \mu \mathrm{L}$ to $1.0 \mathrm{~mL}$ since sufficient sample volume may allow the identification of analytes at a low concentration. The results showed that the signals of eight $\mathrm{CPs}$ increased nearly in ten folds. Considering the sample throughput, the injection volume was not further increased and a sample volume of $1.0 \mathrm{~mL}$ was finally used.

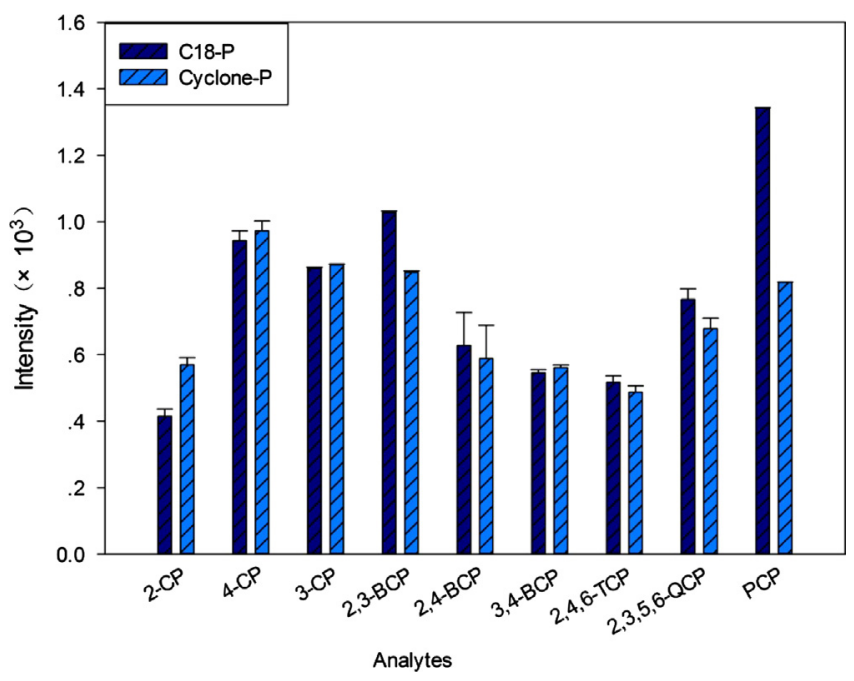

Fig. 2. The extraction efficiencies and relative standard deviations for eight CPS when using two online SPE columns, Turboflow C18-P column $(60 \mu \mathrm{m}$ $1.0 \times 50 \mathrm{~mm})$ and Turboflow Cyclone-P column $(60 \mu \mathrm{m}, 1.0 \times 50 \mathrm{~mm})$. The spiked $1 \mu \mathrm{g} / \mathrm{mL}$ standard solutions was run in replicate $(n=5)$. Sample volume $100 \mu \mathrm{L}$. Sample cleanup with $10 \% \mathrm{ACN}(\mathrm{v} / \mathrm{v}$ ) for $1 \mathrm{~min}$. Sample loading flow rate $2 \mathrm{~mL} / \mathrm{min}$.

\subsection{Loading flow rate}

The loading flow rate affects the turbulent level of samples in the online SPE column, which also determines the efficiency of preconcentration and matrix elimination. Loading flow rates ranging from $2 \mathrm{~mL} / \mathrm{min}$ to $5 \mathrm{~mL} / \mathrm{min}$ were compared. The peak of 2,3,5,6$\mathrm{TeCP}$ disappeared and the peak areas of eight CPs became unstable with a flow rate of $5 \mathrm{~mL} / \mathrm{min}$. 2,3-DCP, 2,4-DCP, 3,4-DCP, 2,4,6-TCP, 2,3,5,6-TeCP and PCP obtained the maximum peak areas and comparable peak areas for $3-\mathrm{CP}$ and $4-\mathrm{CP}$ at $3 \mathrm{~mL} / \mathrm{min}$. The results are shown in Fig. 3. Therefore, a flow rate of $3 \mathrm{~mL} / \mathrm{min}$ was adopted.

\subsection{Sample cleanup}

An appropriate sample cleanup procedure can ensure the responses of the analytes as well as the elimination of matrix components to the fullest extent. Considering that there may be a small amount of protein in urine samples, the proportion of ACN was kept to $10 \%(\mathrm{v} / \mathrm{v})$ to avoid protein deposition, and the washing time was increased. The original washing time was set as $1.0 \mathrm{~min}$. When the washing time was increased to $2 \mathrm{~min}$, the peak area of 3-CP and 4-CP decreased sharply. When it was reduced to $0.5 \mathrm{~min}$,

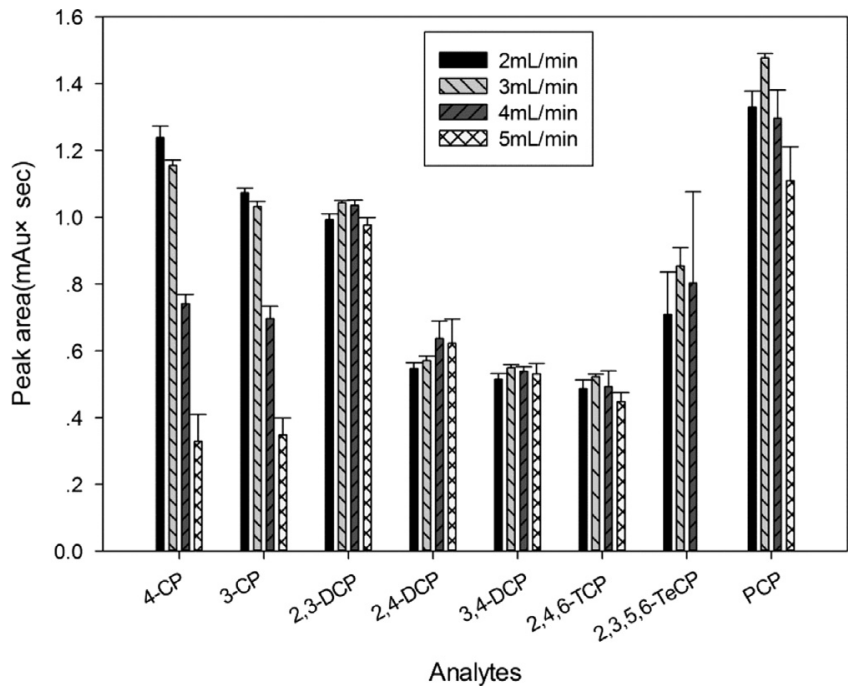

Fig. 3. The response change and relative standard deviations of eight CPs when using different sample flow rates. The spiked $1 \mu \mathrm{g} / \mathrm{mL}$ standard solutions was run in replicate $(n=5)$. Sample volume $100 \mu \mathrm{L}$. Online SPE column: Turboflow C18-P column $(60 \mu \mathrm{m}, 1.0 \times 50 \mathrm{~mm})$. Sample cleanup with $10 \%$ ACN $(\mathrm{v} / \mathrm{v})$ for $1 \mathrm{~min}$.

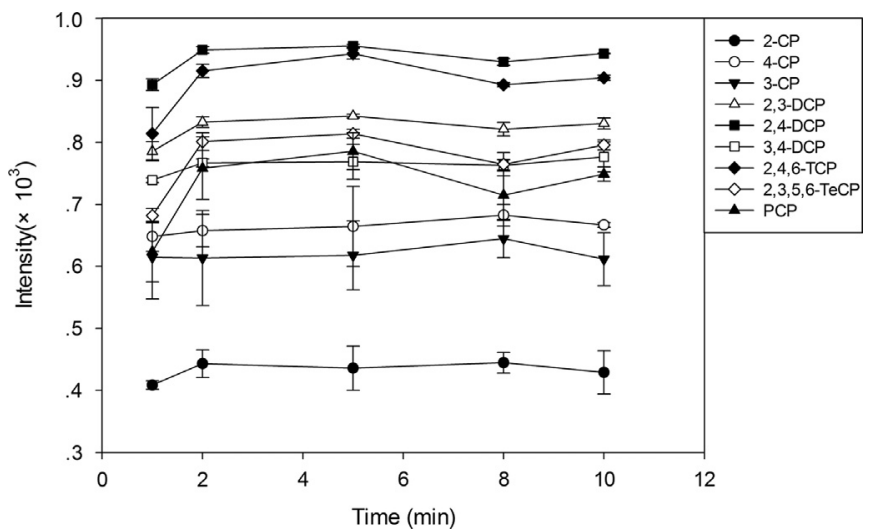

Fig. 4. The response change of eight CPs when using different elution times. The spiked $500 \mathrm{ng} / \mathrm{mL}$ standard solutions was run in replicate $(n=5)$. Sample volume $100 \mu \mathrm{L}$. Online SPE column: Turboflow C18-P column $(60 \mu \mathrm{m}, 1.0 \times 50 \mathrm{~mm})$. Sample cleanup with $10 \% \mathrm{ACN}(\mathrm{v} / \mathrm{v})$ for $1 \mathrm{~min}$. Sample loading flow rate $3 \mathrm{~mL} / \mathrm{min}$. 
the response of the eight analytes was not obviously increased. In order to ensure a sufficient cleanup, $10 \%$ ACN for 1.0 min was used.

\subsection{Elution time}

After cleanup, the valve was switched to elute the analytes from the SPE column to the analytical column for a certain time, and then switched back to reduce matrix effects. The effect of elution time was checked for values of $1-10 \mathrm{~min}$. As shown in Fig. 4, the responses of the eight CPs decreased sharply when the elution time became less than 2 min. Slightly higher values were obtained when elution times equaled $5 \mathrm{~min}$. There was no obvious advantage for elution times of greater than $5 \mathrm{~min}$, and besides, longer elution times may increase matrix effects. Therefore, an elution time of 5 min was used.

\subsection{Quality control and performance of method}

The analytical performance obtained via this online turbulent flow SPE-HPLC/UV is summarized in Table 2. The method was evaluated by its linearity, sensitivity and precision. Seven-point standard curves were constructed by online analysis of standard solutions. Wide linearity ranges were obtained, from the limits of quantification to $1000 \mathrm{ng} / \mathrm{mL}$. The LODs and LOQs were estimated as concentrations, for the signal to noise ratio of 3 and 10 , respectively. The LODs ranged from $0.5 \mathrm{ng} / \mathrm{mL}$ to $2.0 \mathrm{ng} / \mathrm{mL}$, as measured by a UV detector and a $1.0 \mathrm{~mL}$ standard solution. These values were mostly below the existing concentrations in available studies of human exposure $[13,14,19]$. The LODs were comparable to those obtained by LC-MS/MS [4], GC-MS or GC-FID/ECD $[13,41,42]$ analysis. The good sensitivity was attributed to large volume injection and the online SPE procedure. Almost the whole sample was transferred to the analytical column for quantification, instead of a partial extract as in offline methods. The enhancement factors were in the range of 40.6-49.9 (Table 2), which were calculated from the peak areas obtained in the online analysis of standard solution $(1 \mathrm{~mL})$ as percentages of the peak areas obtained in the direct chromatographic injection $(20 \mu \mathrm{L})$ of standard solution with equivalent concentration $(1 \mu \mathrm{g} / \mathrm{mL})$. Excellent coefficients of determination $\left(r^{2}\right)$ were obtained, ranging from 0.9990 to 0.9996 for all standard curves of the eight CPs. The intraday and interday relative standard deviations (RSDs) were assessed by replicate measurements of $100 \mathrm{ng} / \mathrm{mL}$ of standard solutions under optimum conditions within $(n=5)$ and among $(n=5)$ days. The intraday and interday RSDs ranged from $0.6 \%$ to $4.5 \%$. This good reproducibility resulted from minimum manipulation, fewer sources of error, and simple sample pretreatment. Meanwhile, the large particle size $(60 \mu \mathrm{m})$ of the solid phase in the Turboflow C18-P columns at the high flow rate for mobile phase made the urine sample turbulent in the columns, and effectively eliminated matrix components. Thus, the online Turboflow C18-P columns could be reused, with no obvious increase of column pressure and decrease of preconcentration efficiency being found throughout this study.

\subsection{Analysis of urine samples}

In order to evaluate the accuracy of the method, the standard of eight CPs were spiked in a urine sample at 20, 40, and $100 \mathrm{ng} / \mathrm{mL}$, respectively. As showed in Table 2, the spiked recoveries were in the range of 76.3-122.9\%. The good recoveries indicated there was no significant effect from the matrix components of urine. Fig. 5 shows typical chromatograms obtained from unspiked urine samples and those spiked with the eight CPs at $40 \mathrm{ng} / \mathrm{mL}$ and $100 \mathrm{ng} / \mathrm{mL}$.

The optimized method was successfully applied to analyze the eight CPs in 20 urine samples, including ten collected in the hospital, five collected in a rural area, and the other five in our

Table 2

The linearity, reproducibility, LODs and spike recoveries for the eight chlorophenols.

\begin{tabular}{|c|c|c|c|c|c|c|c|c|c|c|c|c|}
\hline \multirow[t]{2}{*}{ Analytes } & \multirow{2}{*}{$\begin{array}{l}\text { Retention } \\
\text { time (min) }\end{array}$} & \multirow[t]{2}{*}{ Calibration curve } & \multirow[t]{2}{*}{$R^{2}$} & \multirow{2}{*}{$\begin{array}{l}\text { Line } \\
\text { range } \\
(\mathrm{ng} / \mathrm{mL})\end{array}$} & \multicolumn{2}{|c|}{$\operatorname{RSD}(\%, n=5)$} & \multirow{2}{*}{$\begin{array}{l}\text { LOD } \\
(\mathrm{ng} / \mathrm{mL})\end{array}$} & \multirow{2}{*}{$\begin{array}{l}\text { Enrichment } \\
\text { factor }\end{array}$} & \multicolumn{3}{|c|}{ Spike recovery $(\%) \pm S D, n g / m L$} & \multirow{2}{*}{$\begin{array}{l}\text { Wavelength } \\
(\mathrm{nm})\end{array}$} \\
\hline & & & & & Intra-day & Inter-day & & & 20 & 40 & 100 & \\
\hline 4-CP & 11.42 & $Y=0.0115 X+0.0816$ & 0.9990 & $1-1000$ & 1.6 & 3.9 & 0.5 & 40.6 & $110.4 \pm 4.0$ & $120.6 \pm 1.5$ & $78.0 \pm 1.1$ & 269.0 \\
\hline $3-\mathrm{CP}$ & 12.33 & $Y=0.013 X+0.0077$ & 0.9991 & $2-1000$ & 1.5 & 3.0 & 1.0 & 47.6 & $111.1 \pm 12.1$ & $80.6 \pm 4.5$ & $97.0 \pm 3.4$ & 277.0 \\
\hline 2,3-DCP & 16.23 & $Y=0.0133 X+0.0068$ & 0.9996 & $1-1000$ & 0.7 & 2.4 & 0.5 & 49.9 & $122.9 \pm 2.4$ & $118.7 \pm 2.1$ & $103.0 \pm 5.2$ & 286.0 \\
\hline 2,4-DCP & 17.56 & $Y=0.0153 X-0.0006$ & 0.9993 & $2-1000$ & 1.4 & 3.0 & 1.0 & 45.7 & $119.2 \pm 0.8$ & $112.6 \pm 2.2$ & $92.4 \pm 0.5$ & 286.0 \\
\hline 3,4-DCP & 19.03 & $Y=0.0125 X-0.0079$ & 0.9995 & $2-1000$ & 0.9 & 4.3 & 1.0 & 41.0 & $104.3 \pm 1.6$ & $114.0 \pm 1.8$ & $95.8 \pm 8.7$ & 286.0 \\
\hline $2,4,6-\mathrm{TCP}$ & 21.37 & $Y=0.0125 X+0.0355$ & 0.9992 & $1-1000$ & 0.8 & 4.0 & 0.5 & 48.9 & $99.3 \pm 1.0$ & $119.0 \pm 1.7$ & $91.5 \pm 1.0$ & 286.0 \\
\hline 2,3,5,6-ТеСР & 23.81 & $Y=0.0106 X+0.0018$ & 0.9990 & $4-1000$ & 4.5 & 0.6 & 2.0 & 43.1 & $76.3 \pm 2.3$ & $95.3 \pm 1.2$ & $85.8 \pm 0.5$ & 303.0 \\
\hline PCP & 24.81 & $Y=0.0072 X+0.0092$ & 0.9995 & $4-1000$ & 1.3 & 3.0 & 2.0 & 45.5 & $110.8 \pm 1.8$ & $119.5 \pm 0.5$ & $93.7 \pm 1.4$ & 303.0 \\
\hline
\end{tabular}

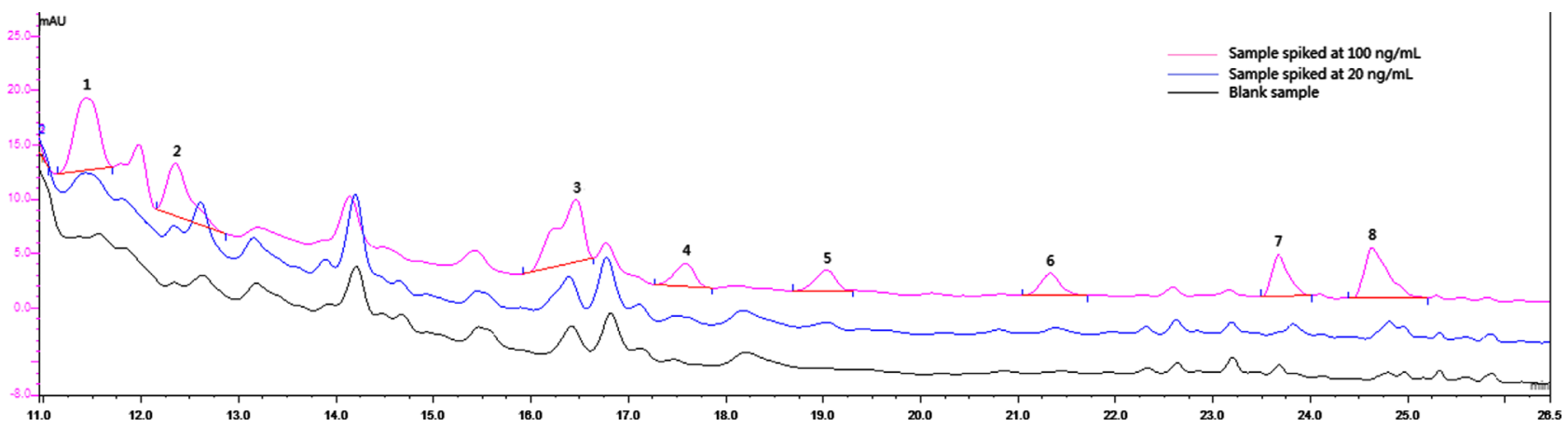

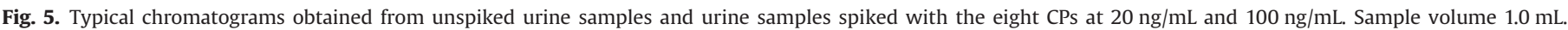
Online SPE column Turboflow C18-P column $(60 \mu \mathrm{m}, 1.0 \times 50 \mathrm{~mm})$. Sample cleanup with $10 \%$ ACN (v/v) for $1 \mathrm{~min}$. Sample loading flow rate $3 \mathrm{~mL} / \mathrm{min}$. 
laboratory. The samples were stored at $-20{ }^{\circ} \mathrm{C}$ and were thawed prior to extraction. All samples were centrifuged $(12,000 \mathrm{r} / \mathrm{min}$, $10 \mathrm{~min}$ ) before analysis. 4-CP, 2, 4-DCP, 3, 4-DCP, 2, 4, 6-TCP, 2, 3, 5, 6 -TeCP, $\mathrm{PCP}$ were not found in all samples. $3-\mathrm{CP}$ was found in one sample collected in hospital, at $12.8 \mathrm{ng} / \mathrm{mL}$. It was also detected in one sample collected in our laboratory, at $31.3 \mathrm{ng} / \mathrm{mL}$, and in one sample collected in the rural area, at $10.9 \mathrm{ng} / \mathrm{mL}$. Moreover, 2, 3-DCP was detected in one sample collected in the rural area, at $7.9 \mathrm{ng} / \mathrm{mL}$. This result was probably attributable to samples obtained from individuals exposed to chlorophenols or to other chlorinated substances that were metabolized into these compounds.

\section{Conclusion}

A fully automatic online turbulent flow SPE-LVI-HPLC/UV method for rapid determination of eight CPs in urine was developed. The complicated matrix components could be effectively eliminated with an online turbulent flow SPE procedure. The procedures of pretreatment and analysis were largely simplified and fully automated. With this method, $1.0 \mathrm{~mL}$ of urine sample could be directly analyzed after centrifugation. Turboflow C18-P columns showed the best extraction efficiency for the target compounds. This simple, automatic, accurate, and low-cost method offers an alternative way to rapidly measure eight CPs in urine samples, especially for screening of occupational exposure. This promising online pretreatment method for complicated matrices may also provide potential applications to other environmental pollutants.

\section{Acknowledgment}

We thank Dr. Li-na Liang and Dr. Yuan-yuan Pan (Thermo Fisher Scientific Incorporation) for their valuable technical support. This work was supported by the Ministry of Science and Technology of China (Nos. 2010DFA92090 and 2012BAK25B01), and the National Natural Science Foundation of China (No. 21377155).

\section{References}

[1] P. de Morais, T. Stoichev, M.C.P. Basto, M.T.S.D. Vasconcelos, Talanta 89 (2012) $1-11$.

[2] D. Li, J. Park, J.R. Oh, Anal Chem. 73 (2001) 3089-3095.

[3] C.M. Santana, M.E.T. Padron, Z.S. Ferrera, J.J.S. Rodriguez, J. Chromatogr. A 1140 (2007) 13-20.

[4] X.Y. Ye, Z. Kuklenyik, L.L. Needham, A.M. Calafat, Anal. Chem. 77 (2005) 5407-5413.
[5] M.C. Jin, Y.W. Yang, Anal. Chim. Acta. 566 (2006) 193-199.

[6] M. Wada, S. Kinoshita, Y. Itayama, N. Kuroda, K. Nakashima, J. Chromatogr. B 721 (1999) 179-186.

[7] K. Pekari, M. Luotamo, J. Jarvisalo, L. Lindroos, A. Aitio, Int. Arch. Occup. Environ. Health 63 (1991) 57-62.

[8] J. Michałowicz, W. Duda, Pol. J. Environ. Stud. 16 (2007) 347-362.

[9] L. Wennrich, P. Popp, M. Moder, Anal. Chem. 72 (2000) 546-551.

[10] N. Campillo, N. Aguinaga, P. Vinas, I. Lopez-Garcia, M. Hernandez-Cordoba, Anal. Chim. Acta. 552 (2005) 182-189.

[11] J.A. Padilla-Sanchez, P. Plaza-Bolanos, R. Romero-Gonzalez, N. Barco-Bonilla, J.L. Martinez-Vidal, A. Garrido-Frenich, Talanta 85 (2011) 2397-2404.

[12] L. Elci, N. Kolbe, S.G. Elci, J.T. Anderson, Talanta 85 (2011) 551-555.

[13] M.A. Crespin, M. Gallego, M. Valcarcel, J. Chromatogr. B 773 (2002) 89-96.

[14] P. Bartels, E. Ebeling, B. Kramer, H. Kruse, N. Osius, K. Vowinkel O. Wassermann, J. Witten, C. Zorn, Fresenius J. Anal. Chem. 365 (1999) 458-464.

[15] F. Navarro-Villoslada, L.V. Perez-Arribas, M.E. Leon-Gonzalez, L.M. Polo-Diez, Anal. Chim. Acta. 381 (1999) 93-102.

[16] M.C. Wei, J.F. Jen, J. Chromatogr. A 1012 (2003) 111-118.

[17] M.C. Quintana, L. Ramos, Trends Anal. Chem. 27 (2008) 418-436.

[18] H. Kontsas, C. Rosenberg, P. Pfaffli, P. Jappinen, Analyst 120 (1995) 1745-1749.

[19] K. Radon, R. Wegner, R. Heinrich-Ramm, X. Baur, B. Poschadel, D. Szadkowski, Am. J. Ind. Med. 45 (2004) 440-445.

[20] A. Ribeiro, M.H. Neves, M.F. Almeida, A. Alves, L. Santos, J. Chromatogr. A 975 (2002) 267-274

[21] C.M. Santana, Z.S. Feffera, J.J.S. Rodriguez, Anal. Chim. Acta 524 (2004) 133-139.

[22] S. Morales, P. Canosa, I. Rodriguez, E. Rubi, R. Cela, J. Chromatogr. A 1082 (2005) 128-135

[23] R.M. Callejon, A.M. Troncoso, M.L. Morales, Talanta 71 (2007) 2092-2097.

[24] S. Insa, V. Salvado, E. Antico, J. Chromatogr. A 1122 (2006) 215-221.

[25] M.C. Jin, Y. Zhu, J. Chromatogr. A 1118 (2006) 111-117.

[26] A. Kramer, J. Angerer, Fresenius J. Anal. Chem. 351 (1995) 327-330.

[27] M.R. Criado, S.P. da Torre, I.R. Pereiro, R.C. Torrijos, J. Chromatogr. A 1024 (2004) 155-163.

[28] L. Oliferova, M. Statkus, G. Tsysin, Y. Zolotov, Talanta 72 (2007) 1386-1391.

[29] X.Y. Ye, K. Zsuzsanna, L.L. Needham, A.M. Calafat, Anal. Bioanal. Chem. 383 (2005) 638-644.

[30] M.M. Galera, D.B. Martinez, P.P. Vazquez, M.D.G. Garcia, J. Sep. Sci. 28 (2005 2259-2267.

[31] L. Couchman, Biomed. Chromatogr. 26 (2012) 892-905.

[32] L. Couchman, M. Birch, R. Ireland, A. Corrigan, S. Wickramasinghe, D. Josephs, J. Spicer, R.J. Flanagan, Anal. Bioanal. Chem. 403 (2012) 1685-1695.

[33] L. Couchman, S.L. Buckner, P.E. Morgan, M.M. Ceesay, A. Pagliuca, R.J. Flanagan, Anal. Bioanal. Chem. 404 (2012) 513-523.

[34] N. Brignol, R. Bakhtiar, L. Dou, T. Majumdar, F.L.S. Tse, Rapid Commun. Mass Spectrom. 14 (2000) 141-149.

[35] J.F. Byrd, B. Yu, S.J. Sheng, Clin. Biochem. 45 (2012), pp. 1103.

[36] F. Perez, M. Llorca, M. Farre, D. Barcelo, Anal. Bioanal. Chem. 402 (2012) 2369-2378.

[37] R. Lopez-Serna, M. Petrovic, D. Barcelo, J. Chromatogr. A 1252 (2012) 115-129.

[38] F. Guo, Q. Liu, G.B. Qu, S.J. Song, J.T. Sun, J.B. Shi, G.B. Jiang, J. Chromatogr. A1281 (2013) 9-18.

[39] Q. Liu, J.B. Shi, L.X. Zeng, T. Wang, Y.O. Cai, G.B. Jiang, J. Chromatogr. A 1218 (2011) 197-204.

[40] T. Bernsmann, P. Furst, M. Godula, Food Addit. Contam. A 28 (2011) $1352-1363$.

[41] H. Bagheri, A. Mir, E. Babanezhad, Anal. Chim. Acta. 532 (2005) 89-95.

[42] N. Fattahi, Y. Assadi, M.R.M. Hosseini, E.Z. Jahromi, J. Chromatogr. A 1157 (2007) 23-29. 